\title{
Seeing Red Over Black and White: \\ Popular and Media Representations of \\ Inter-racial Relationships as Precursors to Racial Violence
}

\author{
Dr. Barbara Perry \\ University of Ontario Institute of Technology \\ Dr. Michael Sutton \\ Nottingham-Trent University
}

The recent murder in the UK of Anthony Walker attests to the lingering antipathy, indeed hostility, toward intimate inter-racial relationships, especially those involving black men and white women. Seventeen year-old Walker was brutally beaten then fatally assaulted with an axe to his head - the "provocation" for the attack was this young black man's relationship with his white girl friend. This paper assesses the historical and contemporary images and mythologies that continue to stigmatize inter-racial relationships. Specifically, we look at the representations disseminated through varied popular media forms. The paper suggests that these mediated constructs condition an environment that facilitates, if not encourages, violence against those in inter-racial relationships.

Remember those wonderful Saturday mornings as a child, when you were firmly planted in front of the television watching cartoons? Do you remember, specifically, watching Krazy Kat? It was a typical cat and mouse cartoon, much like Tom and Jerry, right? Apparently not. In retrospect, with the wisdom of middle age, we can now see the raced, gendered and sexed undertones that permeated that "study in black and white.” While not the first, Krazy Kat was perhaps the most creative "documentary” of images of intimate inter-racial relationships (IIR) in the media.

The authors of this chapter have been exploring the issue of public responses - including violent responses - to IIRs for some time now. One of the issues that arises with some regularity is the foundation for what have typically been negative reactions to black-white IIRs. Undoubtedly, the basis is to be found in associated cultural images. And while these emerge in myriad sites - legislation, political rhetoric, and white supremacist websites, for example - our present interest is in media representations of IIRs that reinforce the images of IIRs as dysfunctional at best, dangerous transgressions at worst. The prevailing trend has been to either 
deny the existence of IIRs by rendering them invisible, or to portray them as "unnatural" border crossings. What we offer here are some tentative first thoughts on media representations of IIRs. We say "tentative" here because there is a glaring paucity of literature from which we are able to draw conclusions. While racialized images have been the focus of considerable inquiry, this analysis has not extended to how these images bleed into representations of inter-racial relationships.

Our paper opens with a consideration of the role of controlling myths in shaping our perceptions of difference. In particular, we emphasize the ways in which cultural constructions of race and gender set up the context in which IIRs are subsequently enacted and perceived. We turn then to the heart of the paper: observations on the ways in which the noted images are portrayed in one cultural form, that is, the media. While there are some exceptions, the tendency has been to portray IIRs in very derogatory ways, whether as inherently doomed, or as inherently dangerous to "racial purity." We close with a brief discussion of how these widespread mythologies might inform subsequent violence against those involved in IIRs in the real - as opposed to mediated - world.

\section{Border Crossing}

The hostility toward interracial relationships and interracial sexuality is ultimately grounded in the essentialist understanding of racial difference. Boundary crossing is thus not only unnatural, but threatening to the rigid hierarchies which have been built around these presumed differences. This sentiment is evident in a letter to the editor written in response to a photo of black and white youths dancing together:

Interracial marriages are unbiblical and immoral. God created different races of people and placed them amongst themselves ... There is nothing for white 
Americans to gain by mixing their blood with blood of other peoples. There will only be irreversible damage for us (cited in Mathabane and Mathabane, 1992: 186).

The essentialist, mutually exclusive categories of belonging that frame hostility toward those in IIRs assume an either/or understanding of identity, in which one is forced to choose "a side." Discrete, "normally" impermeable boundaries are assumed. Consequently, identity formation is often concerned with "drawing boundaries, engaging in boundedness, configuring rings around" the categories of difference (Weis, Proweller and Centrie, 1997:214). The task of difference, then, is to police the borders between categories. There is no room for elision or "border crossing," since this would threaten the "natural" order.

Either side of these borders is significant to the extent that each is "posted" with exclusionary signs that keep whites on one side of the fence, and blacks on the other. They are integral, then, in creating the boundaries that inform public responses to IIRs.

When speaking of IIRs, sexuality becomes a particularly important “construction site.” Every culture can be characterized by a series of definitions of "appropriate" and "inappropriate" sexual forms. Specifically, those definitions "provide permissions, prohibitions, limits and possibilities” with respect to activities, partners and objects of sexuality (Messerschmidt, 1993:73). Given these definitions - which typically include prohibitions on interracial couplings certain behaviors and identities become marginalized at best, stigmatized and demonized at worst. Again, whatever is outside the norm is considered deviant, the negative Other, and therefore subordinate on the hierarchy of sexuality.

Popular culture - including the media - is integral in reinforcing these prohibitions. Goldberg (1990: 297) describes a relatively consistent discursive formation characterized by 
... a totality of ordered relations and correlations - of subjects to each other and to objects; of economic production and reproduction, cultural symbolism, and signification; of laws and moral rules; of social, political, economic or legal inclusion and exclusion. The socio-discursive formation consists of a range of rules: “is's” and “oughts,” "do's” and “dont’s,” "cans” and "cannots,” "thou shalts" and "thou shalt nots."

Popular culture thus plays a vital role in reminding black and white people alike that "thou shalt not" cross the boundaries of sexuality which have been built up since the first black slave was brought to these shores. From the perspective - historical and contemporary - of white Americans, one of the most palpable realms of difference between "us" and "them” lies in sexuality. And it is in this context that people of color - and people who transgress the boundaries - are often subject to the most vicious opprobrium and hostility precedent to racial violence. While they are perceived generally as threatening - in economic, political and social terms - they are especially to be feared, ridiculed and censured on the basis of their presumed sexualities. Black male sexuality is constructed as a "dangerous, powerful and uncivilized force that is hazardous to white women and a serious threat to white men” (Daniels, 1997: 93). Moreover, women of color are also feared and reviled on the same basis: they are racialized, exotic Others who do not fit the Western ideal of womanhood. Whether male or female, people of color - and their white partners - are most at risk of public opprobrium when they visibly cross the racialized sexual boundaries by engaging in interracial relationships.

On the basis of these controlling images of people of color, white women and especially white men are fearful and suspicious of the sexualities of the Other. Speaking of the white fear of black bodies in particular, West (1993: 119) contends that this 
... fear is rooted in visceral feelings about black bodies and fueled by sexual myths of black men and women ... either as threatening creatures who have the potential for sexual power over whites, or as harmless, desired underlings of a white culture.

White Western culture has long held to paradoxical controlling images of the sexualities of people of color. Foremost among these has been the tendency to imagine people of color as "excessive, animalistic, or exotic in contrast to the ostensibly restrained or "civilized" sexuality of white women and men” (Frankenberg, 1993: 75). At different times, in different contexts, most non-white groups have been perceived as sexual predators, guided by their animal-like instincts. Since all but the white race were historically held to be subhuman creatures anyway, it was a small step to paint the Others' sexuality in similar terms. Unlike their white superiors, people of color had not learned to tame their sexual desires, nor to direct them toward “appropriate” objects, i.e., members of their own race.

Nowhere have white fears been more palpable than in their historical relationship with black males. No other group has been so narrowly defined by their sexuality as have black males. This was clear under slavery, where "bucks" were valued for their breeding capacity, but also where black male subordination was justified on the grounds of his savage and beastly nature. As Messerschmidt (1997: 23) contends, black masculinity was irrevocably defined in terms of black sexuality, which in turn, was seen as "animalistic and bestial.” Thus, the unrestrained instincts and desires of black men could be reined in only through the use or threat of violence.

The sexualized image of black males was reproduced in post-bellum culture. In fact, to the extent that black sexual independence was correlated with their economic and political 
freedom, they presented an even greater threat to white masculine superiority. The fact that alleged black rapists were as often castrated as lynched suggests an attempt to emasculate the “savage” by symbolically (and literally) erasing his identity - much as one would control a wild dog. The vicious forms of punishment meted out to black males served to highlight their animal nature, at the same time that it reinforced the power and hegemony of white males.

Consequently,

Both race and masculine difference were reproduced through the practice of lynching and castration and ultimately emasculating the African American male body (Messerschmidt, 1997: 36).

The presumption of black male as sexual predator continues to underlie racial difference and racial violence in the contemporary era. In fact, the myth of lascivious, rapacious and insatiable black sexuality is perhaps one of the most enduring themes in Western racialized cultures. It emerged in the 1988 Willie Horton ads; it was also evoked even by Clarence Thomas' claim that he was the victim of a "hi-tech" lynching; and it ensured Mike Tyson's conviction for sexual assault. The image of the black sexual predator is the cultural lens through which whites perceive blacks. It is difficult, if not impossible, to see interracial relationships as anything other than a threat under the weight of such an age old historical legacy.

\section{Creating the Images}

The above mentioned popular images of IIRs find their way into the popular imagination in myriad ways. They float freely in casual conversation; they find their way into sermons from the pulpits of many religions; they have, in the past, been embedded in anti-miscegenation legislation. The focus, here, however, is on the ways in which the media (mis)represent IIRs. Most striking, perhaps, is the relative absence of IIRs across media forms. As bell hooks reminds 
us, "True love in television and movies is almost always an occurrence between those who share the same race. When love happens across boundaries as in The Bodyguard, Zebraland, or A Bronx Tale, it is doomed for no apparent reason and/or has tragic consequences” (hooks, 1995, 113). This contrasts with data on the actual rates of inter-racial marriage, for example. U.S. census figures reveal that approximately 10 percent of marriages are inter-racial (Nagel, 2003, p24). In the U.S., in marriages between Black and White people, the odds are 3 to 1 that the wife will be White. In the UK, specifically in Greater London, twice as many Black men as Black women are in an IIRs. Out of the 363,000 Black/White marriages in existence in the U.S. in 2000, 73.8 percent of them were comprised of a Black husband and White wife.

These patterns tend not to be reflected in media representations of IIRs. Such media couplings have been rare historically. This invisibility has, in fact, been mandated by various state and local laws. A 1930 Mississippi state law expressly forbade and literature involving inter-racial marriage. Hollywood's Production Code banned "miscegenation" in film from the 1930s until the 1950s.

Ironically, the medium which seems to have garnered the most scholarly attention is the medium that probably has the least impact on audiences. Analyses of IIRs in literature are arguably the most common academic forays into this area. Yet readership remains very low in both the United States and the UK. A recent report by the National Endowment for the Arts, found that less than half of the population polled in 2002 had read any literature (i.e., novels) in the preceding year - down 10 percentage points from 1992 . Only $12 \%$ and $4 \%$, respectively, indicated that they had read poetry or plays (National Endowment for the Arts, 2004).

While tragic for a number of reasons, the low levels of reading also suggest that looking to literature as a key source and support for popular images of interracial mixing is misplaced. 
The irony is that this has, historically, been among the richest sources of both the celebration and denigration of IIRs. Anti-slavery literature, for example, was replete with characters who successfully crossed the colour line; of course, detractors also had their literary outlets (SanchezEppler, (2000). "Southern fiction” generally tended to explore almost obsessively interracialism, intimate and otherwise (Arbery, 2000). So threatening was even the hint of miscegenation that Mississippi, for one, legislated in 1930 against the mention of interracial marriage in any piece of literature.

Ironically, in light of such legislation, positive portrayals of IIRs were rare even then. Both white and black writers railed against mixed-race relationships in their fiction. Jerome B. Holgate's A Sojourn in the City of Amalgamation (1935) was an early dystopian novel featuring rampant IIRs; a modern parallel is to be found in William Pierce's The Turner Diaries (1978). Black authors, too, wrote disparagingly of boundary crossing. A 1967 novel by John Olliver Killens, 'Sippi, "portrays interracial intimacy as an infantile phase that many black men go through before taking on the serious responsibilities of racial loyalty and leadership” (Kennedy, 2003: 134). Sadly, even those novels whose central theme revolves around a critique of racism like those of William Faulkner - tend to reproduce images of IIRs that treat it as "a problem - a problem, moreover, surrounded by shame, misery, ostracism, violence, and death” (Kennedy, 2003: 135). In short, pessimism prevails even in those works that recognize the cultural constructs that give rise to the divisions between black and white.

Contemporary audiences are much more likely to turn to electronic media for their entertainment (NEA, 2004). ${ }^{1} \mathrm{TV}$ and film are the media of choice for the vast majority of

\footnotetext{
${ }^{1}$ The NEA report claims that "the decline in reading correlates with increased participation in a variety of electronic media, including the Internet, video games, and portable digital devices” (NEA, 2004: xii). This paper makes no attempt to explore the themes of IIRs in these electronic alternatives, focusing instead on television and film. If the literature on these is sparse, that on new electronic media is virtually non-existent.
} 
Americans and Brits. And looking at these, it is clear that depictions of IIRs are rare, and where they appear, not entirely flattering. We look first at television programming. In the opening paragraph, we referred to the Krazy Kat cartoon. Meant as much - perhaps more - for adults as for children, Krazy Kat was a conscious statement on race and gender by its creator, George Herriman. It is remarkable, in retrospect, that it survived the censors' scissors. This is perhaps testament to the subtlety of the cartoon's writing. Here we have a complicated interspecies - and interracial - love triangle involving a black (African American judging by the dialect) cat, a white mouse, and a white dog (also a police officer). In some respects, the cartoon was selfconsciously autobiographical: “the playful universe of Krazy Kat can be linked to Herriman’s life as a mixed race individual living in a world where people were forced to be either black or white” (Heer, 2005: 11). Krazy Kat is particularly refreshing if one considers its counterparts of the day. Written during the 1930s and 1940s, this was a subtly anti-racist tract, surrounded by largely conservative comic strips, as evidenced, for example, but the frequently racist caricatures and dialogue of the likes of Bugs Bunny cartoons.

After Krazy Kat, it would be many years, decades, in fact, before IIRs would be even suggested on the small screen. The historical trend has been toward marginalizing, if not excluding IIRs generally. In the contemporary era, consider the ever popular soap operas. In spite of their daytime showing, these programs do not shy away from highly charged intimate relationships or overt sexuality. Among TV genres, they excel in the portrayal of intimate relationships generally. Yet they rarely feature inter-racial relationships. General Hospital did carry an interracial story line for some time. However, this was the exception, rather than the rule. Bramlett-Solomon and Farwell (1997) found no examples of IIRs in their study of 132 
hours of soaps, over an 8 week period. Even for this often risqué genre, IIRs appear to be a taboo subject area.

Day time talk shows are especially complicit in characterizing IIRs as inherently dysfunctional and in fact dangerous for those engaged in such. Motivated by the desire to provide titillating morality plays, shows like Geraldo, Dr. Phil, even Oprah, tend to be dominated by inter-racial couples who have experienced censure rather than support, tragedy rather than joy. The message that results from this consistently negative imagery is that IIRs are "unnatural” and incapable of long term success. So great is the raced and gendered border crossing that participants could not hope to survive the leap. In Race Mixing, Renee Romano reports the experiences of IIR couples she had interviewed. Many of these had been rejected from inclusion on such shows because their stories were not exciting, that is, because they had not experienced widespread problems in their interactions with others or between themselves:

A white man married to a black woman felt as though he and his wife had been asked to participate in a freak show rather than a serious discussion of the issues of being an interracial couple. Producers of the Geraldo show were "very disappointed that there was nothing weird about our relationship and that we were accepted by all the people that we socialize with and work for” ( Romano, 2003: 277-278).

This is obviously not the stuff of day time TV, which thrives on controversy and pain. The audience does not tune in to hear about others' successes, but about their failures. Consequently, as Romano concluded from her interviews, "a show on dysfunctional interracial relationships may serve to stigmatize all who are intermarried by giving credence to negative stereotypes that still circulate in the wider society” (Romano, 2003: 278).

To be fair, recent years have seen some shift, some willingness to push the boundaries of 
viewers' tolerance. Prime time television, for instance, has moved toward greater diversity in it portrayal of intimate relationships. Some very popular and very successful television shows have integrated either ongoing or single episode relationships between black and white individuals. As Romano (2003: 275) notes,

While a single touch between black and white singers on a television show elicited howls of protest in the 1960s, by 1975 it was possible to feature a married interracial couple on a regular television series. The Jeffersons, which premiered in 1975 and ran for ten years, featured Tom and Helen Willis, a white man and black woman, who were the neighbors and friends of George and Helen Jefferson.

More recent programming has also introduced interracial story lines. Ratings winners like $L A$ Law, Ally McBeal, West Wing, and Sex in the City have all featured interracial relationships with little evidence that they suffered subsequent loss of viewers. While generally portrayed as relatively unproblematic relationships, the fact that they are treated as exceptional within the plot attests to the fact that they continue to be seen as abnormal, if not "freakish.” Rather than being woven seamlessly into the ensemble of the cast, they become the storyline.

The advertising that accompanies television programming adds an interesting piece to the mix. Typically, couples shopping for cars, or appliances, or other household goods are same race, and also typically, white. Few campaigns risk social censure - and worse, loss of consumers - by featuring characters who do not represent the norm. Consider Visa's commercials featuring the New York Yankees’ Derek Jeter. He is seen to be out on the town, moving from up-scale bar to up-scale bar, always in the company of very light skinned but still "black" women. This stands in stark opposition to his "real life" experiences, in that Jeter is well known to have had relationships with white women as well as women of colour - so well known 
that he has received death threats accusing him of being a race traitor. It suggests that this very mainstream corporation was unwilling to risk a campaign that might challenge the public's tolerance for racial transgression.

To be commercially successful, cinematic films also tread a very thin line around racial themes. This has not always been the case. In the early days of film, the likes of D.W. Griffith were not at all demure in their attacks on interracial relationships. In 1915, Griffith’s Birth of a Nation offered what amounted to the very first cinematic scene of interracial sexuality. However, what was portrayed was not so much a loving IIR as a stereotypical representation of the salacious black male (white actor in blackface) stalking and threatening the virginal white woman. This fit quite nicely with the sentiment of the day, reinforcing as it did the standard perception of animalistic black men. It would also set the tone for film treatment of IIRs that emphasized the historical continuity of the predatory black male, but not the parallel theme of the sexual exploitation of black women. That we have not come very far is evident in the 1995 movie, Just Cause, which is the modern day parallel to Birth of a Nation. Here, too, sexual relations between blacks and whites are characterized as violent, involuntary couplings dominated by the "black rapist-cum-murderer” (Courtney, 2005: xvi).

In the interim between Birth of a Nation and Just Cause, there have been successive attempts to present both disparaging and sympathetic portrayals of IIRs, with the former predominating. As noted previously, there was a gap between the 1930s and the 1950s when the Production Code mitigated against movies with “offensive” themes like miscegenation. Not surprisingly, perhaps, with the eradication of the Code in 1950,

Interracial tropes examined in earlier periods return with a vengeance in attempts to fortify increasingly beleaguered white male subjects facing increasing demands for racial justice 
and a host of gender pressures. And when old methods repeatedly fail, new and sometimes drastic measures are taken to restore white male privilege and vision (Courtney, 2005: 16). The demise of the Production Code unleashed a veritable duel between pro- and antimiscegenation themes. Most memorable and lasting was of course, Guess Who's Coming to Dinner. This was a ground-breaking film, in that it directly confronted the American psyche with the "challenge" of interracial marriage. It offered a fictional scenario responding to the often asked question "what if your daughter wanted to marry a black man." More significantly, it "represented a very public refutation of the long-accepted white position on interracial marriage. It not only argued that interracial relationships could be healthy, but also suggested that social opprobrium should not prevent couples from marrying and placed whites who opposed interracial relationships as wrong” (Romano, 2003: 204). Yet it did so in a relatively safe, neutral way. There was no intimation of sexuality. The relationship between the central characters was chaste, with only fleeting kiss seen through a rear view mirror. Thus, the "threat" was minimized.

Contrast Guess Who's Coming to Dinner to more recent fare, which is characterized by some diversity in its treatment of IIRs. There are those that seem to reproduce the 1950s “innocence.” In The Pelican Brief, for example, Denzel Washington and Julia Roberts’ characters share only a platonic relationship, while the novel featured a romantic involvement. Jungle Fever, on the other hand, has been widely criticized for denying the viability of blackwhite relationships. Different still are feature films in which the relationships between black and white characters are explicitly eroticized - films like Bad Company, One Night Stand, and Bulworth. Perhaps more promising are those, such as The Bodyguard, in which "interracial intimacy is of little or no significance. This is an important development because presuming the 
normalcy of interracial intimacy - treating it as "no big deal” - may be more subversive of traditional norms than stressing the racial heterodoxy of such relationships” (Kennedy, 2003:

133). Still, such representations are disturbingly few.

\section{From Image to Action}

White and black people learning lessons from mass media about racial bonding are taught that curiosity about those who are racially different can be expressed as long as boundaries are not actually crossed and no genuine intimacy emerges (hooks, 1995: 113).

Should the "lessons" alluded to by hooks not be learned - whether on the screen or on the street - the potential consequences are dire. Both on film and on the street, those engaged in or perceived to be engaged in, intimate interracial relationships are subject to ridicule, abuse, even violence. This was the tragic lesson learned by black murder victims Anthony Walker, killed in Merseyside (UK) in 2005 and Jody-Gaye Bailey, killed in Florida in 2006. Both were killed by young white men offended by their relationships with white men and women. The most dramatic illustration are the murders committed by Joseph Paul Franklin - it is estimated that between 1977 and 1980 he took the lives of thirteen the black and white victims, all of whom had been involved in interracial relationships.

Among the potential effects of the media tendency to stigmatize or demonize IIRs is that it contributes to a culture that bestows "permission to hate," indeed, permission to engage in hate crime. As Snow et al. (1986: 464) have argued, the media frames that we have pointed to here do more than provide entertainment, and even more than shape perceptions; they can also serve as a "guide to action." Media constructs define and assess their objects, but they also "suggest remedies” (Entman, cited in Greenberg, 2002). Among the remedies available for re-aligning intimate relationships that have blurred raced and sexed positions is bias motivated violence. 
That media images are at least complicit in this is clear, though not self-evident. Earlier, we referred to Romano’s (2003) interviews with interracial couples. One such couple claimed that the film Jungle Fever had given racists - black and white alike - a weapon to use against them. They were frequently met with taunts using the title as a sobriquet for their transgressive behaviour. Similarly, Mark Mathabane, writing of his own experiences as part of a mixed race couple, found that he and his wife became the focus of attention as they left the theatre after viewing the same movie.

To the extent that individuals or groups "perform" in ways that corresponds to the "mythical norm" or in ways that correspond to normative - as given by the media - conceptions of one's identity construct, they are held to be doing difference appropriately (Messerschmidt, 1997). In so doing, they uphold the boundaries that separate them from the Other, and ultimately the social relations of power. Conversely, when individuals or groups cross those boundaries, when they fail to perform their identity in normative ways, they are held to be doing difference inappropriately, and thereby leave themselves open to censure. Indeed, where they appear to personify the stigmatized characterizations seen through the media lens, they are especially likely to evoke hostility, and occasionally, violence:

Racialized depictions of sexual purity, dangerousness, appetites, desirability, perversion are part of the performative construction of sexual respectability and disreputability, normalcy and deviance. Ethnosexual frontiers are exotic, but volatile social spaces, fertile sites for the eruption of violence. Racial, ethnic, or nationalist defense and enforcement of in-group sexual honor and purity strengthens ethnic boundaries and subjugates members enclosed inside ethnic borders. . Negative images or accusations about the sexuality of ethnic Others contribute to the creation of disreputable and toxic outgroups and can be 
used to justify their exclusion, repression, or extermination (Nagel, 2003: 55).

In such a context, those perceived to be publicly involved in IIRs may become vulnerable to attack. With this in mind, Miller’s (1995:57) questions can be answered:

... when does ... confrontation with difference have negative effects: when does it lead to great difficulty, deterioration, and distortion, and to some of the worst forms of degradation, terror and violence - both for individuals and for groups that human beings can experience?

The answer: when boundaries are threatened, when men or women, black or white, forget their place, when they reach across raced borders and dare to become intimately involved with the "wrong” person. The threat must be repressed, and, in the context of IIRs, raced boundaries of sexuality preserved. It is here that hate crime can emerge as a response to in the media portrayal of these "unnatural” relationships, as a punishment for those in the real world who have chosen an inappropriate partner. Within the essentialist understanding of identities, there is very little space for ambiguity, or for crossing the boundaries between categories of difference. In other words, accountability involves the assessment of behavior as either conforming or deviating from culturally normative standards. Whenever we "do difference” - which is a recurring effort - we leave ourselves open to reward or censure. So it is that we are discouraged from the "attempt to cross the line, to transgress, desert or quit” (Bourdieu, cited in Fine, 1997:58).

One of the threads that binds together the cultural images highlighted above is the coconstruction of the black sexual predator and the white savior. At the height of white resistance to black citizenship, South Carolina Senator Bill Tillman expressed the black threat and the white response: 
The white women of the South are in a state of siege ... Some lurking demon who has watched for the opportunity seizes her; she is ravished, her body prostituted, her purity destroyed, her chastity taken from her ... So far as I am concerned he has put himself outside the pale of the law, human and divine ... We revert to the impulse to "kill, kill, kill” (cited in Wiegman, 1993: 237-238). Only through avenging the "defilement" of the white woman can the white male reclaim his appropriate position as the "protector" and "savior" of white women. This simultaneously reflects the black male image of "evil" and the white male image of "goodness" (and of course white women as defenseless). As noted above, especially in discussing film portrayals, this theme has been an historical constant.

Fine et al. (1997: 57-58) uncovered contemporary evidence of this dichotomization in their interviews with white male high school students, who proclaimed both their right and duty to preserve the chastity of white girls, for themselves:

Much expressed racism centers on white men's entitled access to white women, thus serving the dual purpose of fixing black men and white women on a ladder of social relations ... This felt need to protect white girls translates as a code of behavior for white male students. It is the fact that Black men are invading White women, the property of White men, that is at issue here.

In defending their white girls from the unrestrained sexuality of black boys, the white boys are also defending themselves - that is, the sanctity of their own carefully restrained, “civilized,” normative sexuality. These youths are reacting to messages received from the broader culture, including the popular media forums discussed above. Few other interpretations are available to them when a high school principal can ban interracial dating with the disclaimer 
that "It is not that I have anything against interracial dating ... It's just that those black boys really want our white girls” (cited in Fine, 1997: 59).

\section{Next Steps}

What we have offered here is not the definitive last word on the issue of media representations of IIRs. On the contrary, our remarks must be seen as very tentative preliminary observations. What is drastically needed is more extensive research like that done by BramlettSolomon and Farwell (1997) on day time soaps, for example. There have been very few such concrete analyses of media treatment of people in IIRs, or on the media treatment of the dynamics of those relationships. It is quite likely, as we have alluded to, that different media may, in fact, offer quite different representations. There is some evidence to suggest, for example, that TV sitcoms have been sympathetic, but feature films less so in the imagery that they offer. Consequently, the necessary research will involve discrete analyses of specific media, as well as subsequent comparisons of these varied forms.

\section{References}

Arbery, G. C. (2000). Victims of Likeness: Quadroons and Octoroons in Southern Fiction. In W. Sollors (ed.). Interracialism: Black-White Intermarriage in American History, Literature, and Law. New York NY: Oxford University Press. Pp. 393-407.

Bramlett-Solomon, S. and Farwell, T. (1997). Sex on Soaps: An Analysis of Black, White and Interracial Couple Intimacy. In S. Biagi and M. Kern-Foxworth (eds.). Facing Difference: Race, Gender, and Mass Media. Thousand Oaks CA: Pine Forge. Pp. 3-10. Courtney, S. (2005). Hollywood Fantasies of Miscegenation. Princeton NJ: Princeton University 
Press.

Daniels, J. (1997). White Lies: Race, Class, Gender, and Sexuality in White Supremacist

Discourse. New York NY: Routledge.

Fine, M. (1997). Witnessing Whiteness. In M. Fine, L. Weis, L. Powell and L. M. Wong (eds.). Off White: Readings on Race, Power and Society. New York NY: Routledge. pp: 57-65.

Frankenberg, R. (1993). White Women, Race Matters: The Social Construction of Whiteness. Minneapolis MN: University of Minnesota Press.

Goldberg, D. T. (1990). The Social Formation of Racist Discourse. In D. T. Goldberg (ed.), Anatomy of Racism (Minneapolis MN: University of Minnesota Press): 295-318.

Greenberg, J. (2002). Framing and Temporality in Political Cartoons: A Critical Analysis of Visual News Discourse. Canadian Review of Sociology and Anthropology, Vol. 39, No. 2, pp. 181-198.

Heer, J. (2005). The Kolors of Krazy Kat. In B. Blackbeard (ed.). Krazy and Ignatz. Seattle WA: Fantagraphics Books. Pp. 8-15.

hooks, b. (1995). Killing Rage: Ending Racism. New York NY: Henry Holt and Company.

Kennedy, R. (2003). Interracial Intimacies: Sex, Marriage, Identity and Adoption. New York NY: Pantheon.

Mathabane, M. and Mathabane, G. (1992). Love in Black and White: The Triumph of Love over Prejudice and Taboo. New York NY: Harpercollins.

Messerschmidt, J. (1997). Crime as Structured Action. Thousand Oaks CA: Sage.

Miller, N. (1995). Out of the Past: Gay and Lesbian History from 1969 to the Present. New York NY: Vintage Press.

Nagel, J. (2003). Race, Ethnicity and Sexuality: Intimate Intersections, Forbidden Frontiers. 
New York NY: Oxford.

National Endowment for the Arts (2004). Reading at Risk: A Survey of Literary Reading in America. Washington DC: NEA.

Romano, R. (2003). Race Mixing: Black-White Marriage in Postwar America. Cambridge MA: Harvard University Press.

Sanchez-Eppler, K. (2000). Bodily Bonds: The Intersecting Rhetorics of Feminism and Abolition. In W. Sollors (ed.). Interracialism: Black-White Intermarriage in American History, Literature, and Law. New York NY: Oxford University Press. Pp. 408-436.

Snow, D., E.B. Rochford, S.K. Worden and R. D. Benford (1986). Frame alignment process, micromobilization and movement participation. American Sociological Review, Vol. 51, pp. 464-481.

Weigman, R. (1993). The Anatomy of Lynching. In J. Fout and M. S. Tantillo (eds.). American Sexual Politics. Chicago IL: University of Chicago Press. Pp. 223-245.

Weis, L., A. Proweller and C. Centri (1997). Re-examining “A Moment in History:” Loss of Privilege Inside White Working Class Masculinity in the 1990s. In M. Fine, L. Weis, L. Powell and L. M. Wong (eds.). Off White: Readings on Race, Power and Society. New York NY: Routledge. Pp. 210-226.

West, C. (1993). Learning to Talk Race. In R. Gooding-Williams (ed.). Reading Rodney King, Reading Urban Uprisings. New York NY: Routledge. pp: 255-260. 